\title{
Can anxiety increase tremors in patients with Parkinson's disease? An experimental model
}

\author{
Marcos Hortes N. Chagas 1,2, Taís Helena G. F. Oliveira ${ }^{1}$, Ila M. P. Linares'1, Fernanda B. Balarini ${ }^{1}$, \\ Natalia Mota S. Chagas ${ }^{1}$, Vitor Tumas ${ }^{1}$, José Alexandre S. CripPa ${ }^{1}$
}

${ }^{1}$ Department of Neuroscience and Behavioral Sciences, Faculty of Medicine of Ribeirão Preto, University of São Paulo (FMRP-USP), Ribeirão Preto, SP, Brazil.

2 Department of Gerontology, Center for Biological and Health Sciences, Federal University of São Carlos (UFScar), São Carlos, SP, Brazil.

Institution where the study was conducted: University of São Paulo, Department of Neurosciences and Behavioral Sciences,

Hospital das Clínicas, Ribeirão Preto Medical School, Ribeirão Preto, SP, Brazil.

Received: 10/26/16 - Accepted: 06/10/2017

DOl: 10.1590/0101-60830000000126

\begin{abstract}
Background: Among non-motor symptoms of Parkinson's disease (PD), anxiety occurs in up to 67\% of patients. Clinically, PD patients report worsening of tremors in anxiogenic situations. Objective: The aim of this study was to evaluate the association between motor symptoms and anxiety in PD patients and compare their performances with those of healthy volunteers. Methods: Fifteen volunteers with PD and 15 healthy volunteers without clinically significant psychiatric disorders were evaluated. Both groups were subjected to a simulated public speaking test (SPST). The following parameters were measured: visual analog mood scale (VAMS), items related to tremors of UPDRS, bradykinesia tests, blood pressure, and heart rate. Results: Results of repeated measures ANOVA indicated a significant effect on group $\times$ phase interaction $\left(\mathrm{F}_{3.7,105.6}=2.56 ; \mathrm{p}=0.046\right)$ for VAMS anxiety factor. Regarding tremors, ANOVA indicated significant differences in group $\times$ phase interaction $\left(\mathrm{F}_{4.5,121}=2.88 ; \mathrm{p}=0.021\right)$ and between the groups $\left(\mathrm{F}_{1,27}=45.88, \mathrm{p}<0.001\right)$, with differences in the anticipatory phase, performance, and post-speech, compared with those in the baseline. There were no significant differences between the groups with regard to other factors of VAMS, physiological measurements, and bradykinesia. Discussion: Worsening of tremors occurred during SPST, particularly in phases with higher anxiety scores.
\end{abstract}

Chagas MHN et al. / Arch Clin Psychiatry. 2017;44(4):85-8

Keywords: Parkinson's disease, anxiety, simulated public speaking test.

\section{Introduction}

Parkinson's disease (PD) is one of the most common neurological syndromes and is the main cause of Parkinsonism among older people. In Brazil, approximately 3.3\% of the population above age 64 has $\mathrm{PD}^{1}$. Although diagnosis is based on motor symptoms (rigidity, bradykinesia, resting tremor, and postural instability), the presence of non-motor symptoms is common; these symptoms potentiate the disability in PD and may have a major impact on the health and quality of life of patients ${ }^{2}$.

Among the non-motor symptoms, anxiety affects up to $67 \%$ of patients with $\mathrm{PD}^{3}$. Notwithstanding, this topic is still little explored. Studies that have evaluated the prevalence of anxiety disorders in PD patients have reported a high prevalence of anxiety without other symptoms ${ }^{4}$, which indicates the difficulty in characterizing anxiety in PD. Symptoms of anxiety are often related to motor symptoms ${ }^{5}$ and the off period in patients with motor fluctuations ${ }^{6}$, which suggests a close association between these symptoms.

Experimental tests used to induce anxiety in healthy volunteers are available. One of these tests is the simulated public speaking test (SPST), which was developed and validated by Mcnair et al. ${ }^{7}$ and subsequently modified by Guimarães et al. ${ }^{8}$ This clinical anxiety model involves making a speech in front of a video camera; this test has been used in several pharmacological studies in cases of normal anxiety and anxiety disorders, and its validity has been confirmed ${ }^{9}, 10$.

In the clinical setting, patients complain of worsening of tremors in anxiogenic situations; however, the association between these factors remains to be elucidated. Therefore, this study aimed to assess anxiety symptoms (subjective and physiological) and motor symptoms (tremor and bradykinesia) induced in patients with PD using SPST, and their performances were compared with those of healthy individuals without PD.

\section{Methods}

\section{Local and participants}

Fifteen subjects with PD were selected in the Movement Disorders Outpatient Clinic of the Clinics Hospital of the Medical School of Ribeirão Preto at the University of São Paulo (FMRP-USP), and 15 volunteers without PD were included in the control group. The inclusion criteria of the PD group were the following: idiopathic PD, Hoehn and Yahr score of 1-3, absence of marked cognitive impairment according to clinical evaluation, absence of treatment with benzodiazepines and antidepressants, use of stable doses of antiparkinsonian drugs for at least 30 days. The exclusion criteria were the following: atypical parkinsonism, presence of dementia, and/or current psychiatric diagnosis according to the DSM-IV criteria. For the control group, the inclusion criteria were absence of marked cognitive impairment according to clinical evaluation and Mini Mental State Exam ${ }^{11}$, and absence of treatment with benzodiazepines and antidepressants. Elderly people with current psychiatric diagnosis were excluded. Experiments were performed in the psychopharmacology laboratory of FMRP-USP. This study was approved by the local ethics committee (process number - CAAE: 10082712.7.0000.5440) and the volunteers signed an informed consent to participate. Study performed according to the Declaration of Helsinki.

\section{Measurements}

The following parameters were measured:

Visual analog mood scale (VAMS) ${ }^{12}$ translated and adapted to Portuguese ${ }^{13}$ : this scale consisted of 16 pairs of adjectives with 
opposite meanings, and participants indicated how they felt about each of these adjectives at the time of the test. The scale items were divided into four groups: anxiety, sedation, cognitive impairment, and discomfort.

Tapping test (TT): bradykinesia test in which participants were asked to lightly touch two points that are $30 \mathrm{~cm}$ apart. Participants completed 10 cycles (one cycle corresponding to touching both sides of the segment) and the time to perform the task was measured on both sides ${ }^{14}$.

Pronation-supination (PS): bradykinesia test was performed with the participants in a sitting position, in which they were asked to perform 20 cycles of alternately and lightly touching the back of their thighs with the back and palm of their hands ${ }^{14}$.

Tremors: tremors were measured according to items 20 and 21 of the unified Parkinson's disease rating scale (UPDRS) ${ }^{15}$. A score was obtained from the sum of resting tremors and posture/movement in the upper limbs.

\section{Procedures}

STPS is an experimental model to induce anxiety. In this model, the participant is asked to prepare a speech on a neutral subject that is recorded and analyzed by a specialist. During the speech, the subject remains seated in front of a monitor that shows his/ her image, which is captured by a camera positioned above the screen ${ }^{7}$. In this study, the volunteers were asked to perform a 4-min speech on the theme "the transport system in your city". During the procedure, physiological measurements (blood pressure and heart rate) were obtained at different phases of the experiment. Table 1 summarizes the procedure. All PD patients were evaluated in the on state.

Table 1. Timetable of the experimental session (SPST)

\begin{tabular}{|l|c|c|}
\hline Time $(\mathrm{min})$ & Phases & Procedure \\
\hline$-0: 30$ & & \\
\hline$-0: 15$ & Baseline (B) & VAMS, TT, PS, HR, BP, Tremor \\
\hline 0 & Pre-stress (P) & VAMS, TT, PS, HR, BP, Tremor \\
\hline$+0: 10$ & & Instrutions about the SPST \\
\hline$+0: 12$ & & Speech preparation \\
\hline$+0: 14$ & Antecipatory speech (A) & VAMS, TT, PS, HR, BP, Tremor \\
\hline$+0: 25$ & & Start speech \\
\hline$+0: 27$ & Speech performance (S) & VAMS, TT, PS, HR, BP, Tremor \\
\hline$+0: 33$ & & Continuation of speech \\
\hline$+0: 35$ & & End of speech \\
\hline$+0: 40$ & Post-stress 1 (F0) & VAMS, TT, PS, HR, BP, Tremor \\
\hline$+0: 55$ & Post-stress 2 (F1) & VAMS, TT, PS, HR, BP, Tremor \\
\hline
\end{tabular}

VAMS: visual analog mood scale; TT: tapping test; PS: pronation-supination; HR: heart rate; BP: blood pressure.

\section{Statistical analysis}

Clinical and demographic data related to sample pairing were statistically analyzed using Student's t-test for continuous data with normal distribution, non-parametric Mann-Whitney test for continuous data with non-normal distribution, and chi-square test for nominal data.

The differences between the scores of VAMS factors, physiological parameters (blood pressure and heart rate), tremor, and bradykinesia were evaluated using repeated measures analysis of variance (ANOVA) and the phases, groups, and group $\times$ phase interactions were evaluated. When sphericity was violated, the degrees of freedom were corrected using the Huynh-Feldt epsilon.

Statistical analysis was performed using the SPSS software version 21.0 at a significance level of $\mathrm{p}<0.05$.

\section{Results}

\section{Participants}

Table 2 describes the clinical and demographic data of the study sample, consisting of $15 \mathrm{PD}$ patients and 15 control subjects without PD. There were no differences in sex, age, education, and cognition between the groups. The mean score on total UPDRS was 33.73 (SD: \pm 9.92 ). In relation to antiparkinsonian treatment of PD group, most of the patients were using levodopa $(n=14)$, either alone or in combination with other medications. Other medications prescribed for PD treatment were pramipexole $(n=9)$, amantadine $(n=3)$, and selegiline $(n=3)$.

Table 2. Clinical and demographic data stratified by the groups

\begin{tabular}{|l|c|c|c|}
\hline & PD & Control & $p$ \\
\hline $\mathrm{N}$ & 15 & 15 & \\
\hline Male/Female & $10 / 5$ & $9 / 6$ & 0.705 \\
\hline Age in years (SD) & $61.0( \pm 2.04)$ & $63.2( \pm 2.04)$ & 0.439 \\
\hline Years of education (SD) & $7.8( \pm 4.24)$ & $9.9( \pm 4.31)$ & 0.190 \\
\hline MMSE (SD) & $26.8( \pm 2.73)$ & $27.9( \pm 1.75)$ & 0.187 \\
\hline Levodopa equivalent dose (SD) & $736.67( \pm 400.61)$ & - & - \\
\hline
\end{tabular}

SD: standard deviation; MMSE: Mini Mental State Exam.

\section{Psychological and physiological anxiety measures}

Repeated measures ANOVA indicated a significant effect on phase $\left(\mathrm{F}_{3.7,105.6}=7.77 ; \mathrm{p}<0.001\right)$ and group $\times$ phase interaction $\left(\mathrm{F}_{3.7,105.6}=\right.$ 2.56; $\mathrm{p}=0.046$ ) for VAMS anxiety factor (Figure 1 ). However, no difference was found between the groups $\left(\mathrm{F}_{1.28}=0.27, \mathrm{p}=0.608\right)$. With regard to other VAMS factors, there was a significant effect of phase on mental sedation $\left(\mathrm{F}_{4.1,114.9}=3.32 ; \mathrm{p}=0.012\right)$, physical sedation $\left(\mathrm{F}_{4.1,114.3}=4.70 ; \mathrm{p}=0.001\right)$, and other feelings $\left(\mathrm{F}_{4.1,115.4}=2.55 ; \mathrm{p}=\right.$ 0.042 ). However, there were no significant effects of these parameters on group $\times$ phase interaction and the groups.

Repeated measures ANOVA showed a significant effect of phase $\left(\mathrm{F}_{5,140}=4.59, \mathrm{p}=0.001\right)$ on heart rate without differences between the groups or group $\times$ phase interaction. Moreover, there were no differences in systolic or diastolic blood pressure between the phases, groups, or group $\times$ phase interaction.

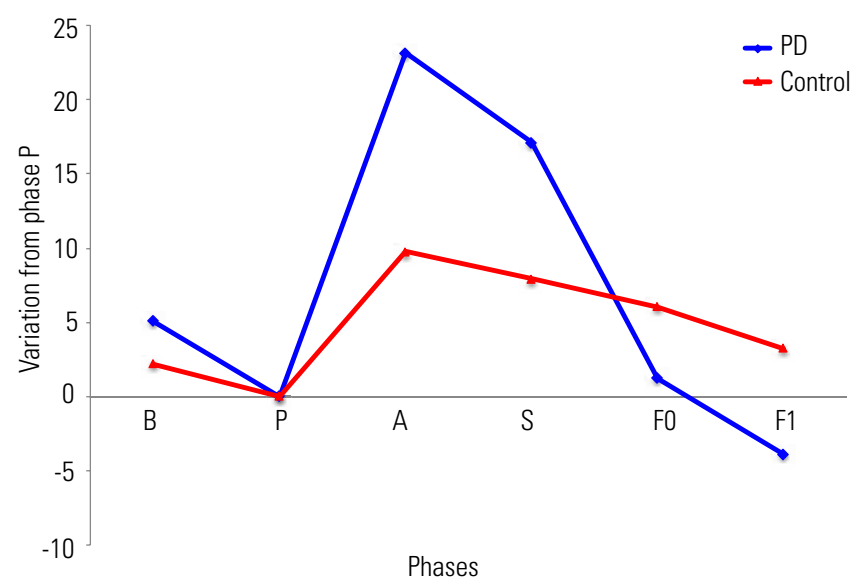

Figure 1. Changes in VAMS anxiety factor induced by SPST, measured in $15 \mathrm{PD}$ patients and 15 healthy subjects. The phases of the experimental session are: B-basal; P-pretest; A-anticipation; S-speech performance; F1-post-speech measures 1; F2-post-speech measures. 


\section{Tremor and bradykinesia}

Repeated measures ANOVA indicated a significant effect of phase on tremors $\left(\mathrm{F}_{4.5,121}=2.42 ; \mathrm{p}=0.046\right)$, group $\times$ phase interaction $\left(\mathrm{F}_{4.5,121}=2.88 ; \mathrm{p}=0.021\right)$ and group $\left(\mathrm{F}_{1,27}=45.88 ; \mathrm{p}<0.001\right)$. The test of contrasts between the phases indicated significant differences between $\mathrm{P}$ and A phases $\left(\mathrm{F}_{1,28}=6.06, \mathrm{p}=0.020\right)$. Results of the paired Student's t-test indicated differences between phases $\mathrm{A}(\mathrm{t}=-3.09 ; \mathrm{p}$ $=0.008), \mathrm{S}(\mathrm{t}=-2.61 ; \mathrm{p}=0.018)$, and F0 $(\mathrm{t}=-2.35 ; \mathrm{p}=0.034)$ and phase $\mathrm{P}$ (Figure 2).

In the bradykinesia tests, repeated measures ANOVA indicated a significant effect of phase for both PS $\left(\mathrm{F}_{1.6,44.4}=10.91 ; \mathrm{p}<0.001\right)$ and TT $\left(\mathrm{F}_{2,55.5}=29.86 ; \mathrm{p}<0.001\right)$ tests without a significant effect on group and group $\times$ phase interaction.

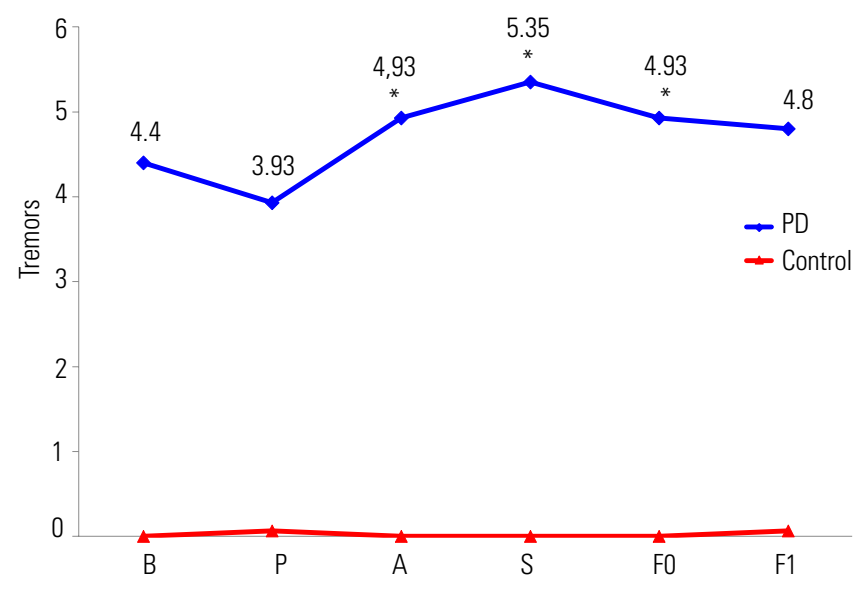

Figure 2. Changes in tremor score during SPST. ${ }^{*} p<0.05$, Student's t test for paired samples (compared with fase P).

\section{Discussion}

Our findings indicate worsening of tremors in phases of higher anxiety scores (phases A and S) during STPS. This result confirms the hypothesis that tremors in PD patients worsen in anxiogenic situations. In addition, there was a statistically significant difference in the group $\times$ phase interaction between the study groups, which suggests anxiety behavior differences between patients with PD and healthy controls.

Several studies have reported an increase in anxiety symptoms in $\mathrm{PD}$ patients, even if these symptoms do not characterize a specific anxiety disorder ${ }^{4}$. These anxiety disorders include social anxiety disorder, which has a high prevalence in patients with $\mathrm{PD}^{16,17}$, possibly by a two-way mechanism, because on the one hand, symptoms of anxiety potentially increase in social-interaction settings, thus leading to increased tremors, and on the other hand, motor symptoms result in negative self-evaluation and increased anxiety.

A recent study reported a correlation among increased levels of anxiety, impaired ability to perform activities of daily living, severity of motor symptoms, and presence of motor fluctuations ${ }^{18}$. Another study evaluated the correlation between virtual reality-induced anxiety and freezing of gait and concluded that anxiety had a strong influence on freezing of gait $^{19}$, thus strengthening the role of the limbic system in the motor symptoms of PD19,20. Most studies that have assessed the association between anxiety and motor symptoms primarily studied motor fluctuations that occurred throughout the day and their association with mood swings and anxiety ${ }^{20-23}$; however, their results were inconclusive, confirming the complexity of this topic.
In situations of anxiety, tremors may be one of the signs of anxiety, even in healthy individuals. Therefore, tremor in patients with PD could be potentiated in anxiogenic situations. Physiologic tremors primarily occur in cases of anxiety and stress, and the use of beta-blockers can be indicated in more severe cases and before important events ${ }^{24}$.

With regard to pathophysiological mechanisms, the regions commonly involved in tremors are the thalamus, basal ganglia, and most of the cortical area via excitatory and inhibitory pathways. Furthermore, the cerebellum and locus coeruleus are a part of this complex mechanism of the motor system ${ }^{24}$. It is of note that these areas are also directly associated with mood symptoms ${ }^{25}$ and anxiety in $\mathrm{PD}^{26}$, thereby corroborating the influence of non-motor symptoms in tremors.

The limitations of this study include the use of UPDRS items alone as a measure to evaluate tremors. As this was an initial study, we sought to assess motor symptoms in general, and an increase in the number of assessments would greatly increase the duration of assessment at each stage of STPS. Moreover, a study is being conducted using accelerometry to evaluate tremors using more objective data. We would like to highlight STPS could be used in future studies as an experimental anxiety model to assess the effect of drugs on tremors induced or exacerbated by anxiogenic situations in patients with PD.

In conclusion, this study showed worsening of tremors during SPST, particularly in phases with higher anxiety scores.

\section{Conflicts of interest}

None.

\section{Acknowledgements}

J.A.S.C are recipients of a Conselho Nacional de Desenvolvimento Científico e Tecnológico (CNPq, Brazil) fellowships award. T. H. G. F. O. was recipient of a FAPESP (São Paulo, Brazil) fellowship (Fapesp process 2012/10483-6).

\section{References}

1. Barbosa MT, Caramelli P, Maia DP, Cunningham MC, Guerra HL, Lima-Costa MF, et al. Parkinsonism and Parkinson's disease in the elderly: a community-based survey in Brazil (the Bambui study). Mov Disord. 2006;21(6):800-8.

2. Soh S-E, Morris ME, McGinley JL. Determinants of health-related quality of life in Parkinson's disease: a systematic review. Parkinsonism Relat Disord. 2011;17(1):1-9.

3. Chagas MHN, Tumas V, Loureiro S, Côrrea A, Nakabayashi T, Crippa J. Does the association between anxiety and Parkinson's disease really exist? A literature review. Curr Psychiatry Rev. 2009;5:29-36

4. Dissanayaka NNNW, White E, O'Sullivan JD, Marsh R, Pachana NA, Byrne GJ. The clinical spectrum of anxiety in Parkinson's disease. Mov Disord. 2014;29:967-75.

5. Dissanayaka NNW, O’Sullivan JD, Pachana NA, Marsh R, Silburn PA, White EX, et al. Disease-specific anxiety symptomatology in Parkinson's disease. Int Psychogeriatr. 2016;28(7):1153-63.

6. Witjas T, Kaphan E, Azulay JP, Blin O, Ceccaldi M, Pouget J, et al. Nonmotor fluctuations in Parkinson's disease: frequent and disabling. Neurology 2002;59:408-13.

7. McNair DM, Frankenthaler LM, Czerlinsky T, White TW, Sasson S, Fisher S. Simulated public speaking as a model of clinical anxiety. Psychopharmacol. 1982;77:7-10.

8. Guimarães FS, Zuardi AW, Graeff FG: Effect of chlorimipramine and maprotiline on experimental anxiety in humans. J Psychopharmacol. 1987;1:184-92.

9. Bergamaschi MM, Queiroz RHC, Chagas MHN, de Oliveira DCG, De Martinis BS, Kapczinski F, et al. Cannabidiol Reduces the Anxiety Induced by Simulated Public Speaking in Treatment-Naïve Social Phobia Patients. Neuropsychopharmacology. 2011;36:1219-26. 
10. Hetem LA, de-Souza CJ, Guimarães FS, Zuardi AW, Graeff FG. D-fenfluramine reduces anxiety induced by simulated public speaking. Braz J Med Biol Res. 1993;26:971-4.

11. Folstein MF, Folstein SE, McHugh PR. "Mini-mental state". A practical method for grading the cognitive state of patients for the clinician. J Psychiatr Res. 1975;12(3):189-98.

12. Norris $\mathrm{H}$. The action of sedatives on brain stem oculomotor systems in man. Neuropharmacology. 1971;10:181-91.

13. Zuardi AW, Karniol I. Estudo Transcultural de uma Escala de Auto-avaliação para estados subjetivos. J Bras Psiquiatr. 1981;31:403-96.

14. Ruiz PJG, Bernardos VS, Bartolomé M, Torres AG. Capit timed tests quantify age-related motor decline in normal subjects. J Neurol Sci. 2007;260:283-5.

15. Fahn S, Elton RL and members of the UPDRS development committee. Unified Parkinson's Disease Rating Scale (UPDRS). In: Fahn S, Marsden CD, Calne DB, Goldstein M editors. Recent Developments in Parkinson's Disease. Florahm Park, N.J.: Macmillan Health Care; 1987.

16. Moriyama TS, Chagas MHN, Silveira-Moriyama L, Tumas V, Lees AJ, Crippa JA, et al. Diagnosing social anxiety in Parkinson's disease: characteristics and frequencies according to two diagnostic criteria. Arch Clin Psychiatry (São Paulo). 2016;43(6):139-42.

17. Broen MPG, Narayen NE, Kuijf ML, Dissanayaka NNW, Leentjens AFG. Prevalence of anxiety in Parkinson's disease: A systematic review and meta-analysis. Mov Disord. 2016;31(8):1125-33.
18. Broen MPG, Köhler S, Moonen AJH, Kuijf ML, Dujardin K, Marsh L, et al. Modeling anxiety in Parkinson's disease. Mov Disord. 2016;31:310-6.

19. Ehgoetz Martens KA, Ellard CG, Almeida QJ. Does anxiety cause freezing of gait in Parkinson's disease? PLoS One. 2014;9:e106561.

20. Ganjavi H, MacDonald PA. ON-OFF Effects of Dopaminergic Therapy on Psychiatric Symptoms in Parkinson's Disease. J Neuropsychiatry Clin Neurosci. 2015;27:e134-9.

21. Leentjens AFG, Dujardin K, Marsh L, Martinez-Martin P, Richard IH, Starkstein SE. Anxiety and motor fluctuations in Parkinson's disease: a cross-sectional observational study. Parkinsonism Relat Disord. 2012;18:1084-8.

22. Richard IH, Frank S, McDermott MP, Wang H, Justus AW, LaDonna KA, et al. The ups and downs of Parkinson disease: a prospective study of mood and anxiety fluctuations. Cogn Behav Neurol. 2004;17:201-7.

23. Storch A, Schneider CB, Wolz M, Stürwald Y, Nebe A, Odin P, et al Nonmotor fluctuations in Parkinson disease: severity and correlation with motor complications. Neurology. 2013;80:800-9.

24. Puschmann A, Wszolek ZK. Diagnosis and treatment of common forms of tremor. Semin Neurol. 2011;31:65-77.

25. Chagas MHN, Linares IMP, Garcia GJ, Hallak JEC, Tumas V, Crippa JAS. Neuroimaging of depression in Parkinson's disease: a review. Int Psychogeriatr. 2013;25:1953-61.

26. Wen M-C, Chan LL, Tan LCS, Tan EK. Depression, anxiety, and apathy in Parkinson's disease: insights from neuroimaging studies. Eur J Neurol. 2016;23:1001-19. 